\title{
La presenza di mutazioni del gene USP8 può predire la sensibilità alla terapia farmacologica degli adenomi ACTH-secernenti nella malattia di Cushing
}

\author{
Salvatore Cannavò ${ }^{1}$
}

Pubblicato online: 20 dicembre 2016

C) Springer International Publishing AG 2016

Commento a:

The USP8 mutational status may predict drug susceptibility in corticotroph adenomas of Cushing's disease.

K. Hayashi, N. Inoshita, K. Kawaguchi, A.I. Ardisasmita, H. Suzuki, N. Fukuhara, M. Okada, H. Nishioka, Yasuhiro Takeuchi, M. Komada, A. Takeshita, S. Yamada.

Eur J Endocrinol (2016) 174:213-226

La malattia di Cushing rappresenta la forma più frequente di ipercortisolismo endogeno ed è causata dall' ipersecrezione di ACTH da parte di un adenoma ipofisario. Mutazioni del gene che codifica per la peptidase ubiquitinospecifica 8 (USP8) sono state recentemente individuate in circa la metà degli adenomi ipofisari ACTH-secernenti e, in particolare, fino al $60 \%$ dei microadenomi. Tali mutazioni provocano la deubiquitinizzazione del recettore per l'Epidermal Growth Factor (EGFR), inducendo un' esagerata sintesi di proopiomelanocortina (POMC) e, conseguentemente, l'ipersecrezione di ACTH $[1,2]$.

In uno studio pubblicato recentemente da Hayashi et al. è stato valutato l'effetto di tali mutazioni sulle caratteristiche clinico-patologiche della malattia di Cushing in 60 pazienti, di cui 15 con adenoma a cellule di Crooke (rara variante caratterizzata da maggiore invasività e aggressività, che in alcuni casi evolve verso il carcinoma). Le mutazioni di USP8 sono state individuate in pazienti di sesso femminile, ad eccezione di un caso, e complessivamente nel 35\% dei casi (nel 13,5\% degli adenomi a cellule di Crooke e nel

$凶$ S. Cannavò

cannavos@unime.it

1 Dipartimento di Medicina Clinica e Sperimentale, Università di Messina, Messina, Italia
42,2\% degli altri tumori). La presenza della mutazione è stata associata a una minore aggressività del tumore, essendo stata evidenziata nei microadenomi ed essendo frequente nei casi con migliore outcome chirurgico. La presenza della mutazione, tuttavia, non è risultata associata con una maggiore espressione di EGFR, anche se i livelli di POMC e l'espressione del sottotipo 5 del recettore per la somatostatina (SSTR5) e di $\mathrm{O}^{6}$-metilguanina DNA metiltransferasi (MGMT) nel tessuto tumorale erano più elevati.

In conclusione, le mutazioni di USP8 sono particolarmente frequenti nei microadenomi ACTH secernenti che dimostrano un'iperespressione di POMC, e possono essere implicate nell'eccessiva secrezione di ACTH. Sebbene non sia dimostrato che tali mutazioni inducano l'ipersecrezione di ACTH attraverso l'attivazione dell'EGFR, esse sembrano predire una migliore risposta alla terapia con pasireotide (analogo della somatostatina caratterizzato da elevata affinità per SSTR5). Al contrario, gli adenomi a cellule di Crooke che non presentano mutazioni di USP8 potrebbero rispondere meglio alla terapia con temozolomide, in quanto la MGMT risulta debolmente espressa.

\section{Bibliografia}

1. Reincke M, Sbiera S, Hayakawa A et al (2015) Mutations in the deubiquitinase gene USP8 cause Cushing's disease. Nat Genet 47:31-38

2. Ma ZY, Song ZJ, Chen JH et al (2015) Recurrent gain-of-function USP8 mutations in Cushing's disease. Cell Res 25:306-317 